\title{
A New Fractal Multiband Antenna for Wireless Power Transmission Applications
}

\author{
Taoufik Benyetho ${ }^{D},{ }^{1}$ Jamal Zbitou, ${ }^{1}$ Larbi El Abdellaoui $(\mathbb{D})$, \\ Hamid Bennis $(\mathbb{D})^{2}$ and Abdelwahed Tribak ${ }^{3}{ }^{3}$ \\ ${ }^{1}$ LMEET, FST of Settat, Hassan 1st University, Settat, Morocco \\ ${ }^{2}$ TIM Research Team, EST of Meknes, Moulay Ismail University, Meknes, Morocco \\ ${ }^{3}$ Microwave Team, INPT, Rabat, Morocco
}

Correspondence should be addressed to Taoufik Benyetho; t.benyetho@gmail.com

Received 24 August 2017; Revised 1 December 2017; Accepted 30 January 2018; Published 14 March 2018

Academic Editor: Gerard Ghibaudo

Copyright (C) 2018 Taoufik Benyetho et al. This is an open access article distributed under the Creative Commons Attribution License, which permits unrestricted use, distribution, and reproduction in any medium, provided the original work is properly cited.

The Microwave Power Transmission (MPT) is the possibility of feeding a system without contact by using microwave energy. The challenge of such system is to increase the efficiency of transmitted energy from the emitter to the load. This can be achieved by rectifying the microwave energy using a rectenna system composed of an antenna of a significant gain associated with a rectifier with a good input impedance matching. In this paper, a new multiband antenna using the microstrip technology and fractal geometry is developed. The fractal antenna is validated into simulation and measurement in the ISM (industrial, scientific, and medical) band at $2.45 \mathrm{GHz}$ and $5.8 \mathrm{GHz}$ and it presents a wide aperture angle with an acceptable gain for both bands. The final antenna is printed over an FR4 substrate with a dimension of $60 \times 30 \mathrm{~mm}^{2}$. These characteristics make the antenna suitable for a multiband rectenna circuit use.

\section{Introduction}

The wireless power transmission concept was introduced in the last decade of the 19th century by Nicola Tesla's experiment in which he tried to light bulbs wirelessly by transmitting energy from distant oscillators operated to $100 \mathrm{MV}$ at $150 \mathrm{KHz}$, but he could not implement his system for commercial use due to its very low efficiency [1]. After this contribution, researchers in Japan [2] and the United States [3] continued to improve the efficiency of wireless power transmission in 1920s and 1930s.

1950 has known the true start of wireless power transmission thanks to the development of high power microwave tubes by Raytheon company [4]. In 1958, a $15 \mathrm{KW}$ microwave tube had measured $81 \%$ DC to RF conversion efficiency $[5,6]$. The first rectenna, conceived also by Raytheon company, came in the early 1960s. This Rectifying Antenna was composed of a half-wave dipole antenna associated with a balanced bridge or semiconductor diode placed over a reflecting plane. A resistive load was then connected to the output of the rectenna. The $2.45 \mathrm{GHz}$ as transmitting frequency was privileged due to its advanced and efficient technology base, its minimal attenuation through the atmosphere even in bad weather, and its location at the center of an industrial, scientific, and medical (ISM) band.

The rectenna's greatest conversion efficiency ever recorded was in 1977 by Brown in Raytheon company [7]. The rectenna operated at $2.45 \mathrm{GHz}$ and reached $90.6 \%$ conversion efficiency with an input power level of $8 \mathrm{~W}$. This rectenna element used GaAs-Pt Schottky barrier diode and aluminum bars to construct the dipole and transmission line. In 1982, 85\% conversion efficiency was achieved, by using a rectenna printed thin film operated at $2.45 \mathrm{GHz}$ [8].

Other frequencies were used to design rectenna circuit like $35 \mathrm{GHz}$ frequency $[9,10]$ which can decrease the transmitting and rectenna aperture areas and then increase the transmission range, but the problem is the high cost and inefficiency of components which generate high power at $35 \mathrm{GHz}$. 


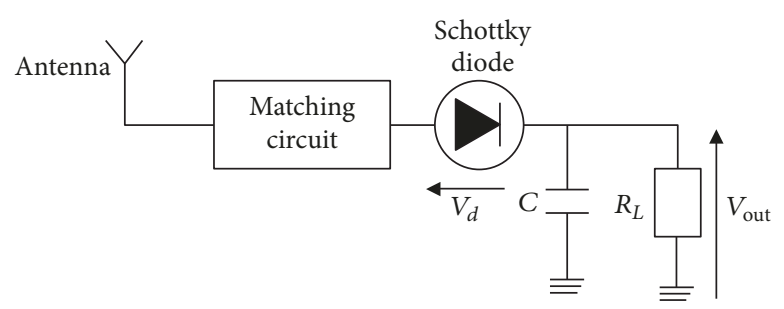

Figure 1: Block diagram of a rectenna circuit [11].

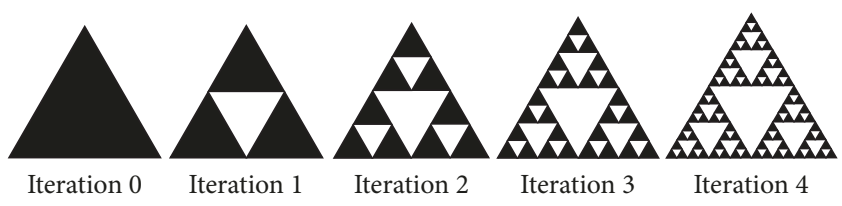

FIgURE 2: Sierpiński triangle at iterations from 0 to 4.

Figure 1 shows basic elements of a rectenna system. A rectenna circuit is composed of an antenna which collects the RF energy and a Schottky diode which rectifies this energy. The matching circuit between the antenna and the diode is a low pass filter designed to pass the fundamental frequency and reject the higher order harmonics generated from the nonlinear Schottky diode. The capacitor between the Schottky diode and the load behaves as a DC pass filter which protects the load from the HF harmonics.

In order to have an efficient rectenna circuit, the antenna must present good performance. A good return loss to avoid reflected energy, a big gain, and wide aperture angles to maximize RF harvested energy. The rectenna conversion efficiency $\eta$ is defined by (1) in [12]:

$$
\eta=\frac{P_{\mathrm{DC}}}{P_{\mathrm{DC}}+P_{\mathrm{LOSS}}}
$$

where $P_{\mathrm{DC}}$ is the output power and $P_{\mathrm{LOSS}}$ is the loss power. Because the rectenna output is a DC power, the output power could be defined by

$$
P_{\mathrm{DC}}=\frac{V_{\text {out }}^{2}}{R_{L}},
$$

where $V_{\text {out }}$ is the output voltage of the rectifier and $R_{L}$ is the load.

When only conduction losses of the diode are considered and all the other losses are neglected, the conversion efficiency can be determined by [12]

$$
\eta=\frac{1}{1+V_{d} / 2 V_{\text {out }}} .
$$

$V_{d}$ is the voltage drop across the conducting diode.

Since its invention, the rectenna was used for various applications like RFID [16], SHARP (Stationary High Altitude Relay Platform) the microwave powered aircraft [17], and Solar Power Satellite (SPS). This last application concept is based on the construction of solar stations with great photovoltaic panels in space which will produce electricity that would be sent directly to Earth by microwaves to replace towers and power lines [18]. Recently, researchers introduced power through $\mathrm{Wi}-\mathrm{Fi}$, which permits charging batteries by Wi-Fi routers transmission [19].

\section{Fractal Antenna Theory}

Fractal antenna is an antenna based on fractal geometry. This term was first used by the French mathematician Mandelbrot in 1975 to describe a fractal shape that can be subdivided in many parts; each one of them is a reduced-size copy of the whole. Fractal term is derived from Latin word "Fractus" meaning "broken" [20]. Since the achievement of the first fractal antenna in 1995 [21], much progress proved that fractal geometry helps reduce antenna size and gives it a multiband behavior [21-25].

The fractal dimension $D$ defined by (4) calculates the irregularity degree and fragmentation of a natural object or a geometric assembly [20]:

$$
D=\frac{\ln (\text { Number of self similar pieces })}{\ln (1 / \text { magnification factor })} \text {. }
$$

The "Number of self similar pieces" represents the number of copies identical to the original shape when applying a fractal aspect from one step (or iteration) to another. The "magnification factor" signifies the scaling value between an iteration and the next one when applying a fractal technique.

The fractal antenna developed in this paper is based on Sierpiński triangle fractal geometry introduced by the Polish mathematician Sierpiński in 1916 [26]. The Sierpiński triangle is obtained from an equilateral triangle by a repeated process or iteration. The first iteration consists of subdividing the equilateral triangle into four smaller congruent equilateral triangles and removing the central one. The result as illustrated in Figure 2 is 3 equilateral triangles with half the size of the original one. 


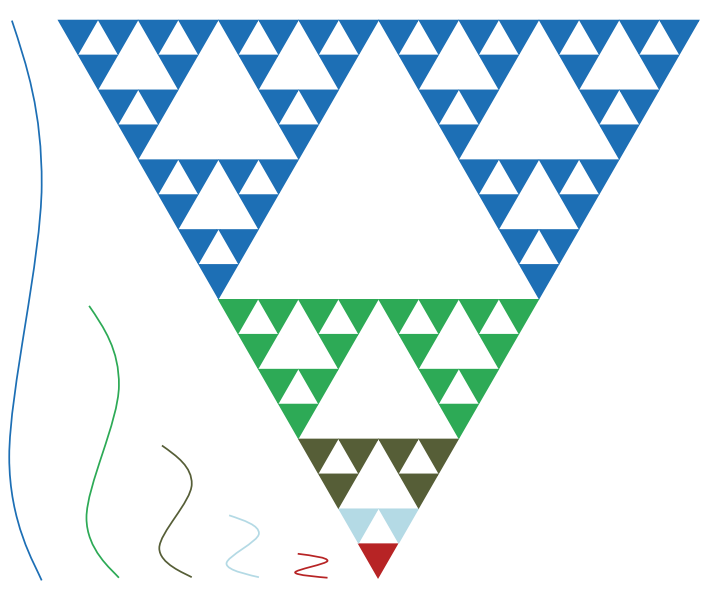

FIgURE 3: Sierpiński triangle multiband behavior.

To reach the second iteration, the same process is applied to the 3 equilateral triangles obtained in the first iteration; the result is 9 triangles and so on.

The number of copies from an iteration to the next one is multiplied by 3 and the size of the triangles is divided by 2 . In consequence, the Sierpiński triangle fractal dimension is

$$
D=\frac{\ln (3)}{\ln (1 /(1 / 2))}=1.58 \text {. }
$$

The Sierpiński triangle is widely used in antenna design due to its multiband behavior. The resonant frequency of an antenna is related to its length. When applying Sierpiński fractal concept to an equilateral triangle, different equilateral triangles with diverse sizes are created that lead to the multiband aspect of Sierpiński triangle antenna as explained in Figure 3.

\section{Antenna Design and Measurement}

3.1. Antenna Design. As explained above, Sierpiński triangle antenna is known for its multiband behavior. Some researches present accurate equations that predict the resonance frequencies of a standard Sierpiński antenna [27]. The problem is that the frequencies are related to the chosen dimensions that are defined in advance, so in order to design a Sierpiński antenna which resonates in frequencies different from those defined by equations, some modification of the standard design must be applied.

As illustrated in Figure 4, three antennas based on Sierpiński triangle at iterations 1,2 , and 3 are designed in order to study the fractal impact over this structure. The designed antennas differ from the standard Sierpiński triangle by the ground which is also a Sierpiński triangle, symmetric to the radiating patch. The substrate is an FR4 with relative permittivity equal to $4.4,1.6 \mathrm{~mm}$ for thickness, and 0.025 for loss tangent. The simulation and optimization of the antenna were done by using CST Microwave Studio software.

Table 1 summarizes the antennas parameters.

Figure 5 shows that the simulated antennas return losses at the three iterations.
TABLE 1: Antennas' dimensions in mm.

\begin{tabular}{lc}
\hline Parameter & Length \\
\hline$a$ & 65 \\
$b$ & 30 \\
$c$ & 26 \\
$d$ & 25.8 \\
$e$ & 1.3 \\
$f$ & 15 \\
$g$ & 4.7 \\
$i$ & 3 \\
$j$ & 3 \\
\hline
\end{tabular}

The three iterations present almost the same behavior in the simulated frequency range. The $-10 \mathrm{~dB}$ simulated return loss bandwidths cover ISM $2.4 \mathrm{GHz}$ and $5.8 \mathrm{GHz}$ bands. From iteration 1 to iteration 3 the resonance frequencies decrease slightly, while the input impedance matching decreases at the lower band and increases at the higher band. It is deduced that applying a fractal aspect over the new Sierpiński triangle designed structure has a very low effect on the return loss results. For more detailed study the $X-Z$ plane and the $Y-Z$ plane radiation pattern as well as the current distribution of the three designed antennas are compared.

Figure 6 shows the antenna radiation pattern comparison of the three iterations at $2.45 \mathrm{GHz}$ and $5.8 \mathrm{GHz}$.

We notice that at $2.4 \mathrm{GHz}$ the three iterations present exactly the same behavior: an omnidirectional propagation in the $Y Z$ plane (a) and a bidirectional radiation through the $Z$-axis $\left(0^{\circ}\right.$ and $\left.180^{\circ}\right)$ in the $X Z$ plane (b).

At $5.8 \mathrm{GHz}$, the radiation pattern difference between the three iterations is very small. In the $Y Z$ plane, the propagation is almost omnidirectional at iterations 1 and 2 with some attenuation through the $Y$-axis and perfectly omnidirectional at iteration 3 but with smaller gain. In the $X Z$ plane, even if the radiation is no longer bidirectional, the maximum of propagation is still through the $Z$-axis $\left(0^{\circ}\right.$ and $\left.180^{\circ}\right)$. 

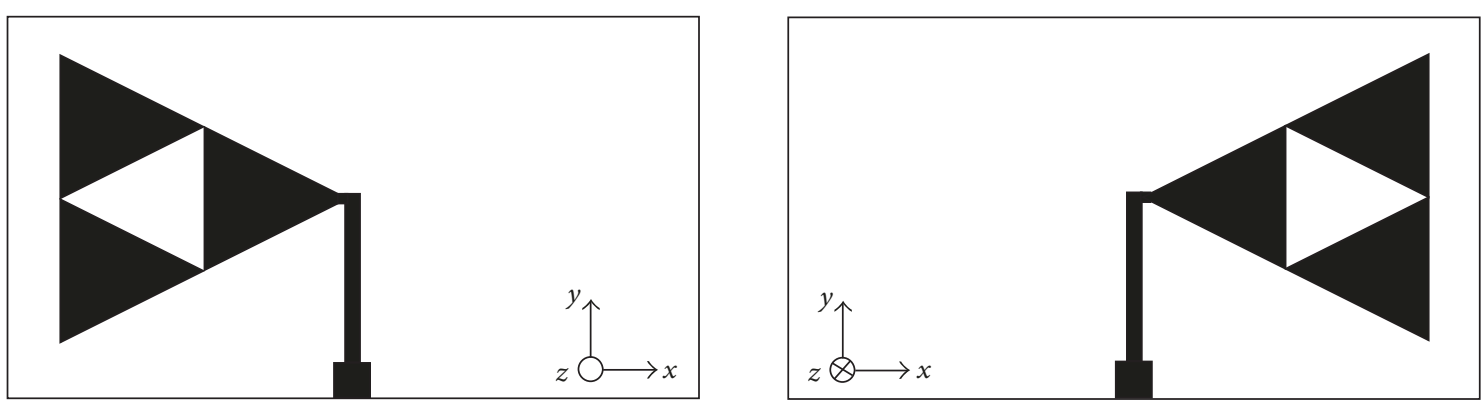

(a)
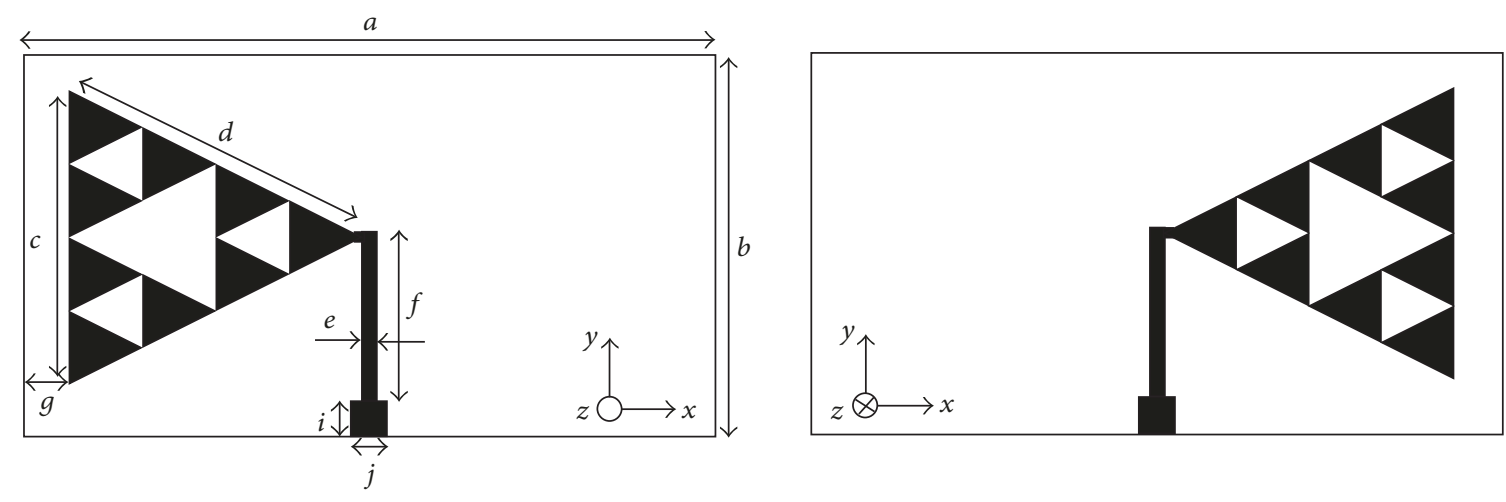

(b)
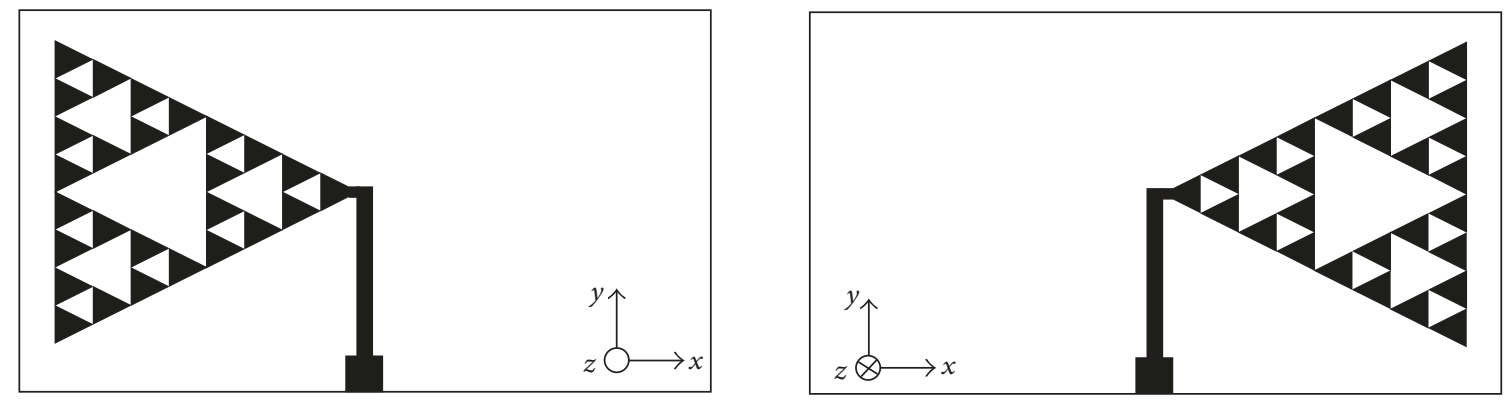

(c)

FIgURE 4: The patch (left) and the ground (right) of the designed antennas: (a) iteration 1, (b) iteration 2, and (c) iteration 3.

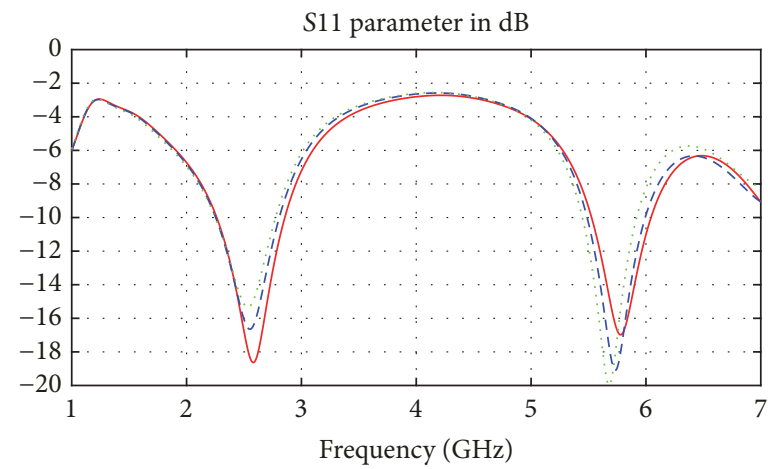

- Iteration 1

- - - Iteration 2 Iteration 3

FIgURE 5: The designed antennas return loss at iterations 1, 2, and 3. 


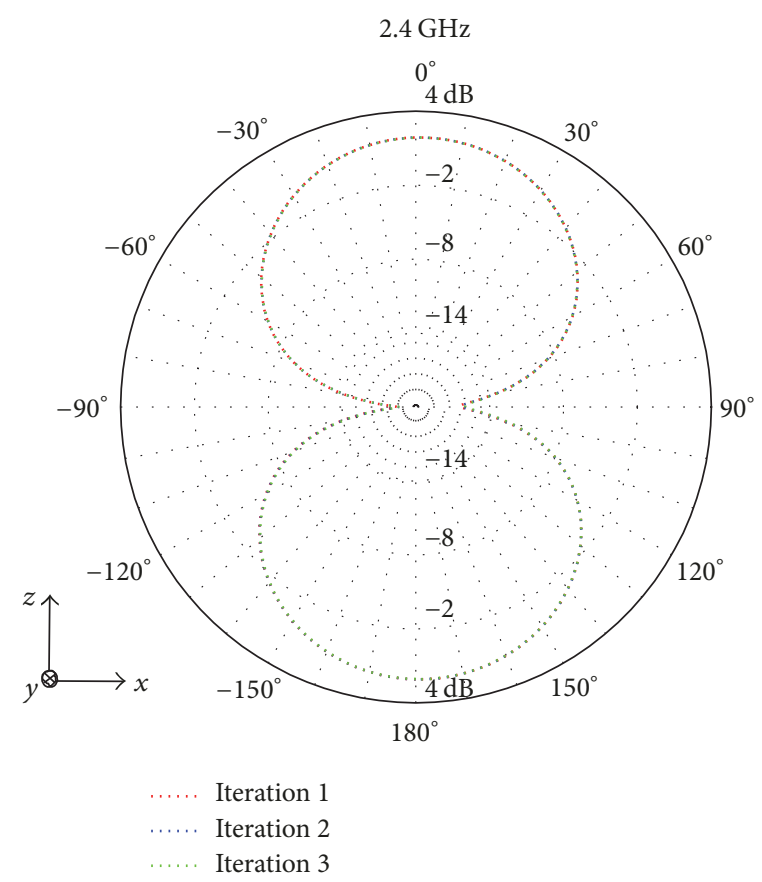

(a)

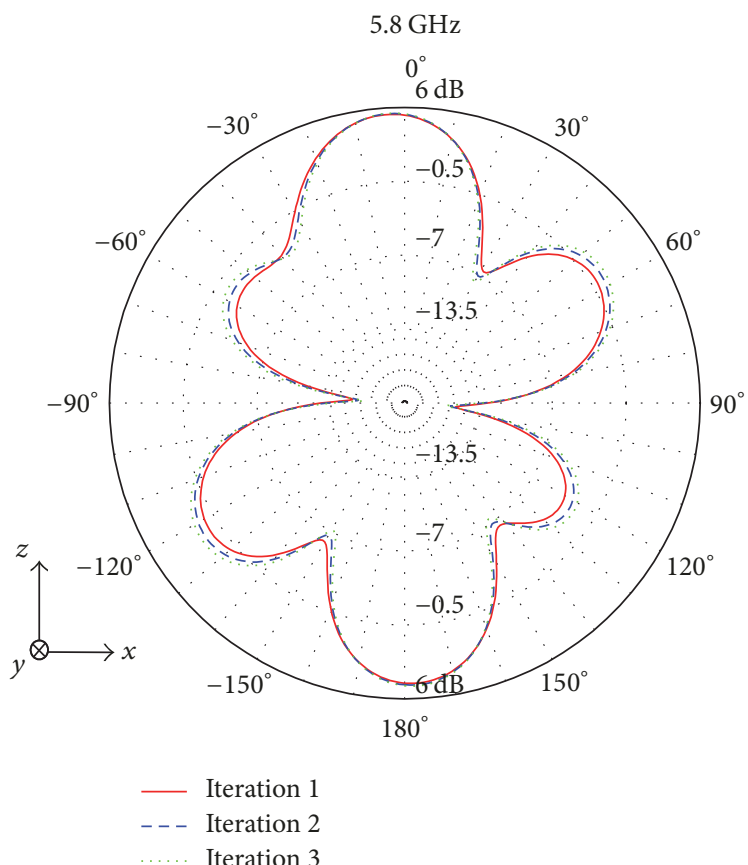

(c)

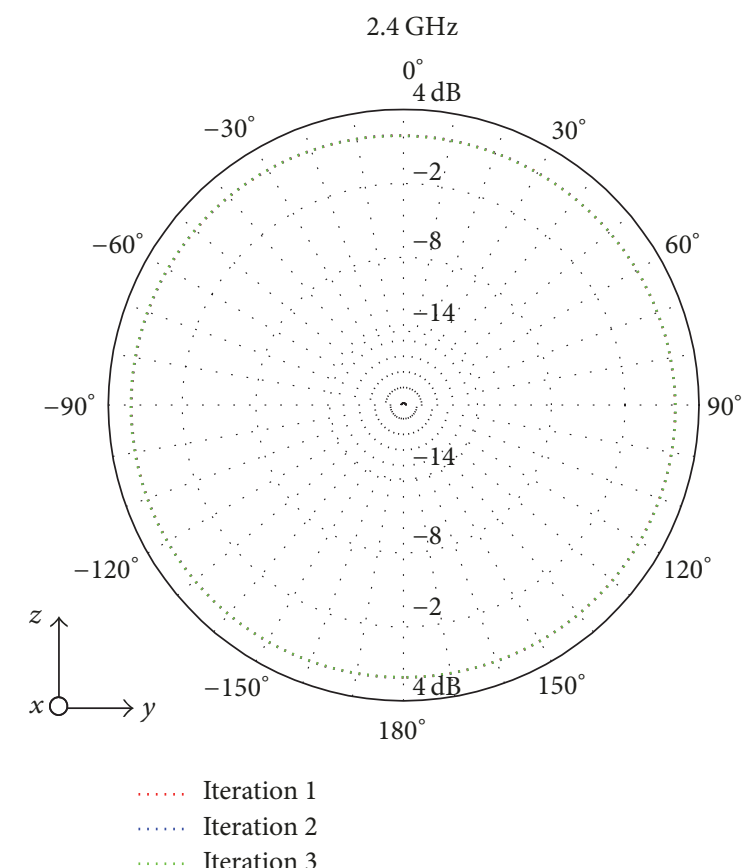

(b)

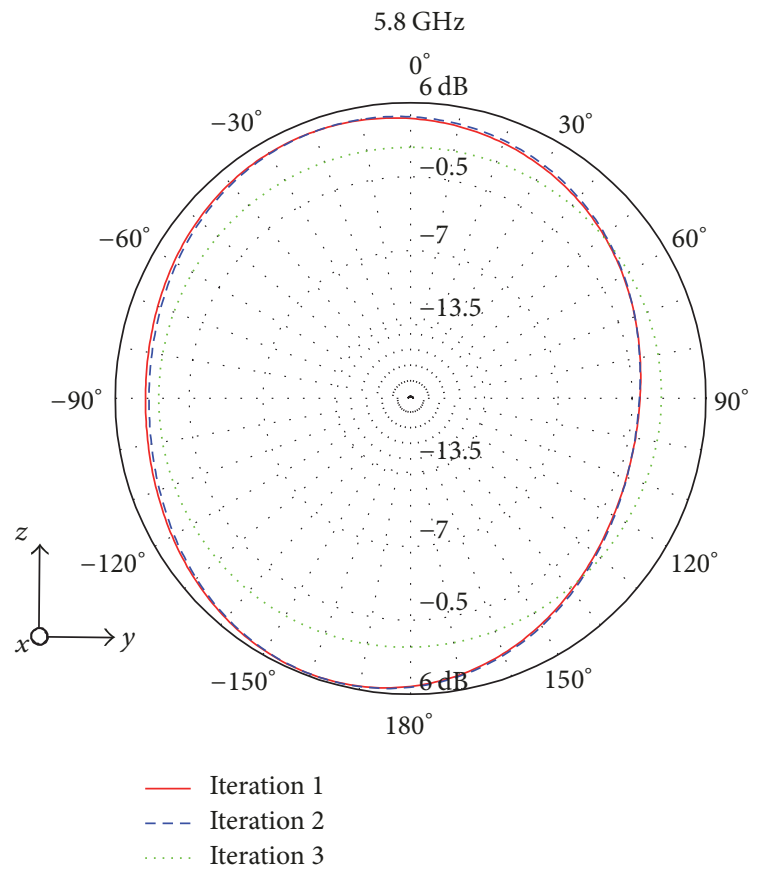

(d)

FIGURE 6: Antenna radiation pattern comparison of the three iterations at $2.4 \mathrm{GHz}$ ( $X Z$ plane (a) and $Y Z$ plane (b)) and $5.8 \mathrm{GHz}(X Z$ plane (c) and $Y Z$ plane (d)).

The simulation shows that the antenna radiation pattern characteristics stay almost stable at both resonance frequencies for the three iterations.

Figure 7 compares the antenna radiation pattern at $2.4 \mathrm{GHz}$ and $5.8 \mathrm{GHz}$ in the $X Z$ plane (a) and $Y Z$ plane (b). In $X Z$ plane, the low gain $(2.1 \mathrm{dBi})$ at the $2.4 \mathrm{GHz}$ is compensated by an aperture angle of $77^{\circ}$ compared to $33^{\circ}$ and a gain of $5.5 \mathrm{dBi}$ at $5.8 \mathrm{GHz}$. In the $Y Z$ plane, the aperture angles at both resonance frequencies are very large. The gain is constant at $2.4 \mathrm{GHz}(2.2 \mathrm{dBi})$ and attains $5.8 \mathrm{dBi}$ at $5.8 \mathrm{GHz}$ with little attenuation through the $Y$-axis.

Figure 8 illustrates the current distribution of the three iterations designed antennas for both bands $2.4 \mathrm{GHz}$ and $5.8 \mathrm{GHz}$. 


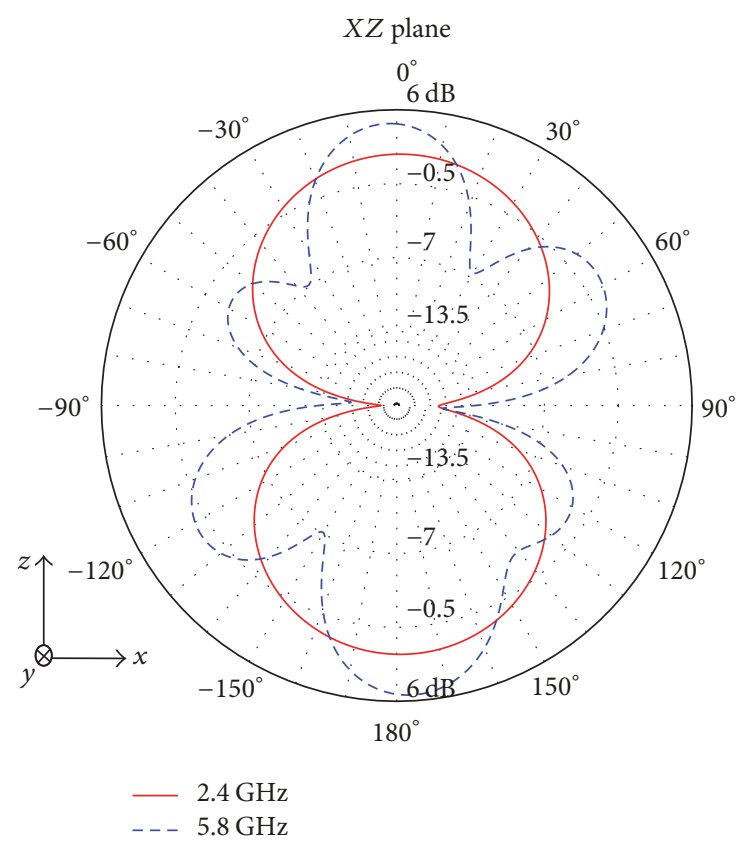

(a)

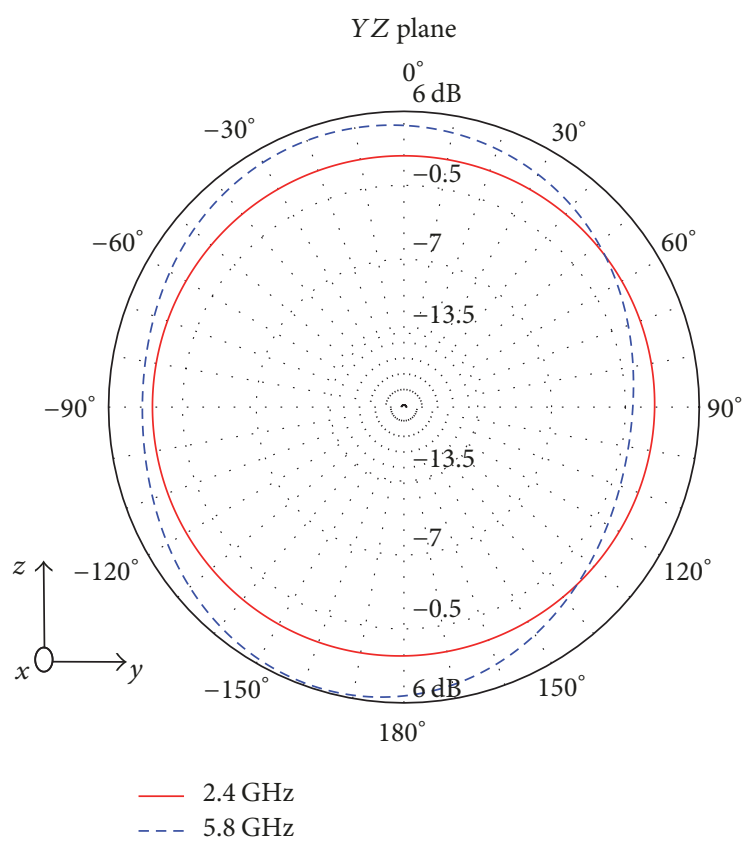

(b)

FIGURE 7: $X-Z$ plane and $Y-Z$ plane designed antennas radiation pattern at $2.45 \mathrm{GHz}$ (a) and $5.8 \mathrm{GHz}$ (b).

The current distribution is the same at the three iterations. At $2.4 \mathrm{GHz}$ the current is distributed over all the structure while at $5.8 \mathrm{GHz}$ it is more distributed in the half of the structure near to the feeding line.

3.2. Results and Discussion. After a study of the designed Sierpiński triangle antennas at the three first iterations, we deduced that the antennas characteristics do not change too much. We then chose to realize the structure at the second iteration as illustrated in Figure 9.
Figure 10 shows a comparison between simulated and measured return loss.

The simulated and measured return losses show good agreement. The slight difference is generally related to connector use which is not considered during simulation. Table 2 gives a numerical comparison of the validated bands.

The $-10 \mathrm{~dB}$ measured return loss bandwidths $(19.5 \%$ and $11.7 \%$ at the low and high resonance frequencies, resp.) cover ISM $2.4 \mathrm{GHz}(2.4-2.5 \mathrm{GHz})$ and $5.8 \mathrm{GHz}(5.725-5.875 \mathrm{GHz})$ bands. 

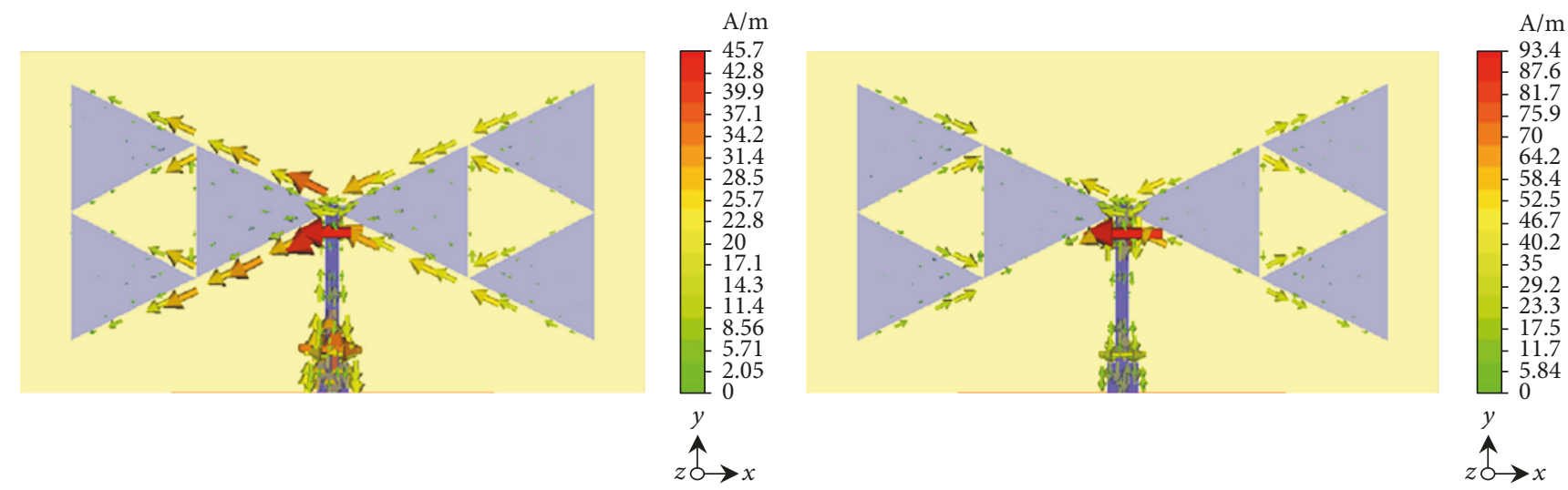

(a)
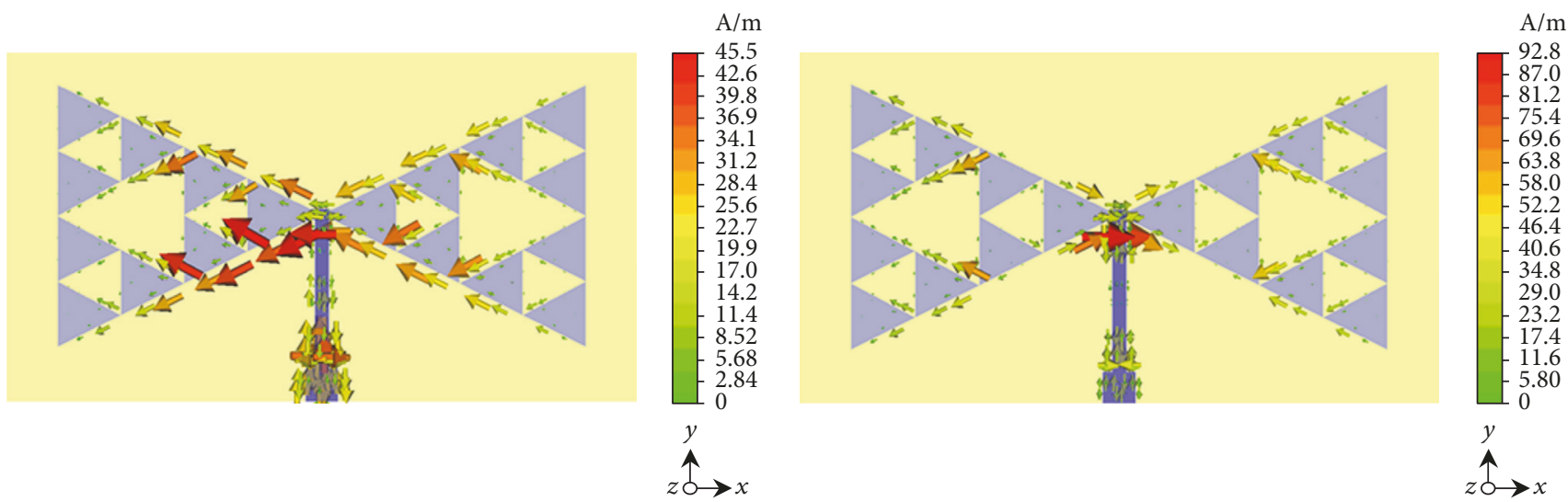

(b)
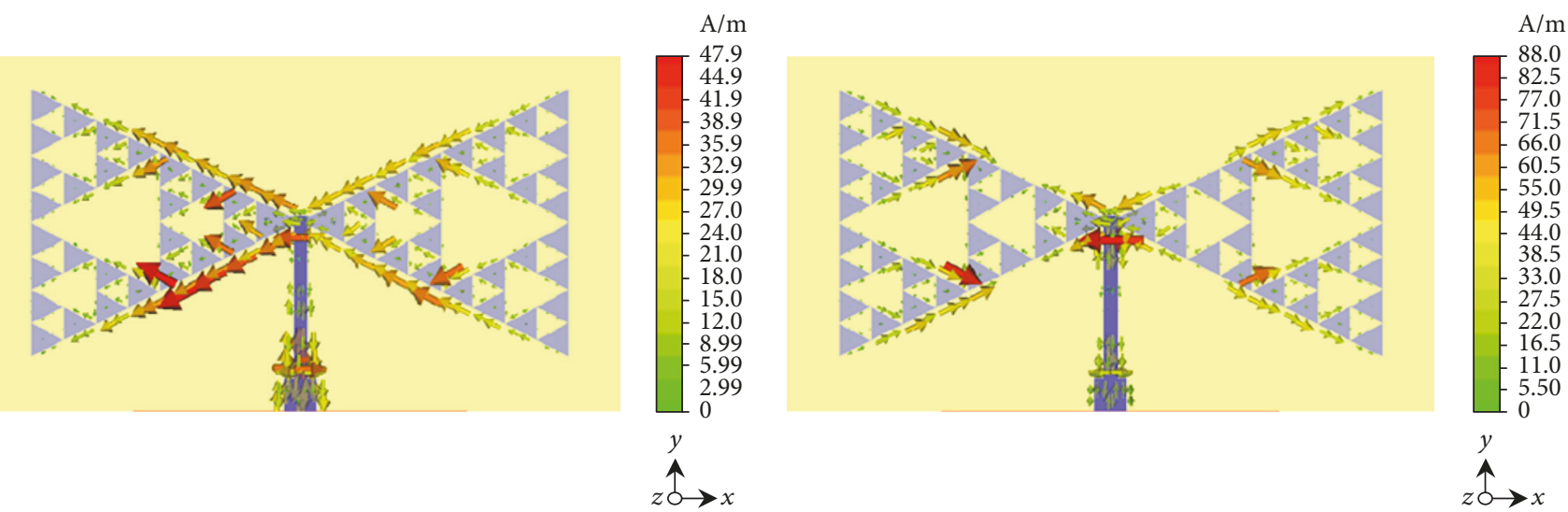

(c)

FIgURE 8: Designed antennas current distribution at $2.45 \mathrm{GHz}$ (left) and $5.8 \mathrm{GHz}$ (right) in iterations 1 (a), 2 (b), and 3 (c).

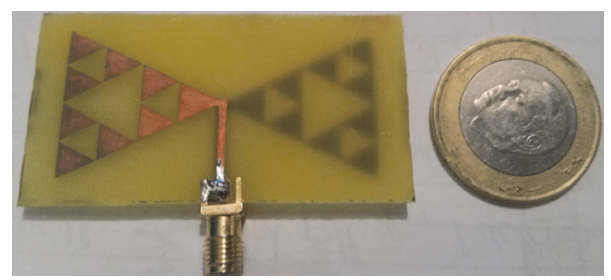

FIGURE 9: Realized antenna picture. 
TABLE 2: Comparison between simulated and measured antenna return losses.

\begin{tabular}{lcr}
\hline Bands & Simulation & Measurement \\
\hline Band 1 & {$[2.25-2.8] \mathrm{GHz}$} & {$[2.35-2.86] \mathrm{GHz}$} \\
Band 2 & {$[5.5-6] \mathrm{GHz}$} & {$[5.48-6.16] \mathrm{GHz}$} \\
\hline
\end{tabular}

TABLE 3: Performance comparison between the proposed antenna and other compact antennas.

\begin{tabular}{lccc}
\hline Published literature versus proposed antenna & Antenna size $\left(\mathrm{mm}^{2}\right)$ & Bands $(\mathrm{GHz})$ & $\mathrm{Gain}(\mathrm{dBi})$ \\
\hline This work & $60 \times 30$ & 5.4 & 2.2 \\
& & 5.2 & 5.8 \\
Reference [13] & $45 \times 30$ & 5.8 & 6.4 \\
& & 1.8 & 3.9 \\
Reference [14] & $45 \times 45$ & 2.4 & 10 \\
Reference [15] & $135 \times 93$ & & \\
\hline
\end{tabular}

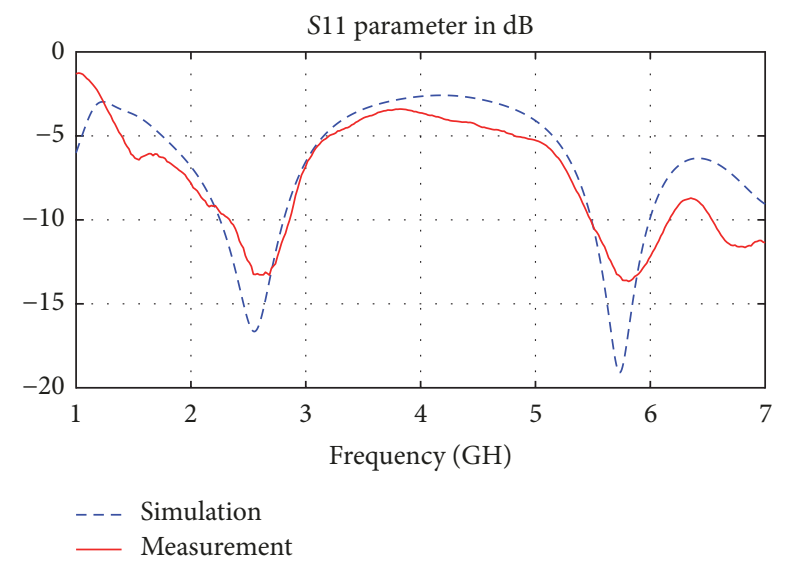

FIGURE 10: Comparison between simulated and measured antenna return loss.

Figure 11 presents the $X Z$ (E-plane) and $Y Z$ (H-plane) planes radiation pattern at frequencies $2.5 \mathrm{GHz}$ (a and c) and $5.8 \mathrm{GHz}$ (b and d).

The measured radiation at $2.5 \mathrm{GHz}$ is distributed over all directions but presents a maximum through the $Z$-axis at $180^{\circ}$ while it is concentrated in the upper part of the $X Z$ plane at $5.8 \mathrm{GHz}$. In the $Y Z$ plane, the antenna radiates in all directions except around $180^{\circ}$ through the $Z$-axis at both $2.5 \mathrm{GHz}$ and $5.8 \mathrm{GHz}$.

We notice that there is considerable radiation attenuation around $180^{\circ}$ relative to the antenna back in the $Y Z$ plane and at $5.8 \mathrm{GHz}$ in the $X Z$ plane. After analysis we deduced that this attenuation is related to mechanical support of measurement that reflects the energy received from the horn antenna when the receiving antenna is turned back.

The achieved antenna presents good characteristics that are suitable for wireless power transmission (WPT) applications. The size is small $\left(60 \times 30 \mathrm{~mm}^{2}\right)$. The dual ISM bands covered by the antenna in this work are commonly used for WPT. The radiation pattern is almost omnidirectional in both bands, which permits harvesting a maximum of energy. The antenna gain could be improved by several techniques.

In [28], authors designed an antenna array (4 elements) with multiple superstrates to improve the Sierpiński triangle antenna gain. The antenna operates at $860 \mathrm{MHz}$ for RFID application. This method could be applied to our structure in order to enhance the gain and then the rectenna efficiency.

Table 3 compares the achieved antenna to other planar antennas used for rectenna application.

\section{Conclusion}

A new planar multiband fractal antenna based on Sierpiński triangle is presented. In the first Sierpiński triangle, three iterations are designed and studied. The second iteration structure was printed over an FR4 substrate of $60 \times 30 \mathrm{~mm}^{2}$ as dimension, a relative permittivity equal to $4.4,1.6 \mathrm{~mm}$ of thickness, and 0.025 of loss tangent. The measurements present good performance at ISM $2.4 \mathrm{GHz}$ and $5.8 \mathrm{GHz}$. The structure is simple to fabricate, low cost, and easy to associate with integrated circuits. These characteristics are suitable for wireless power transmission applications. 


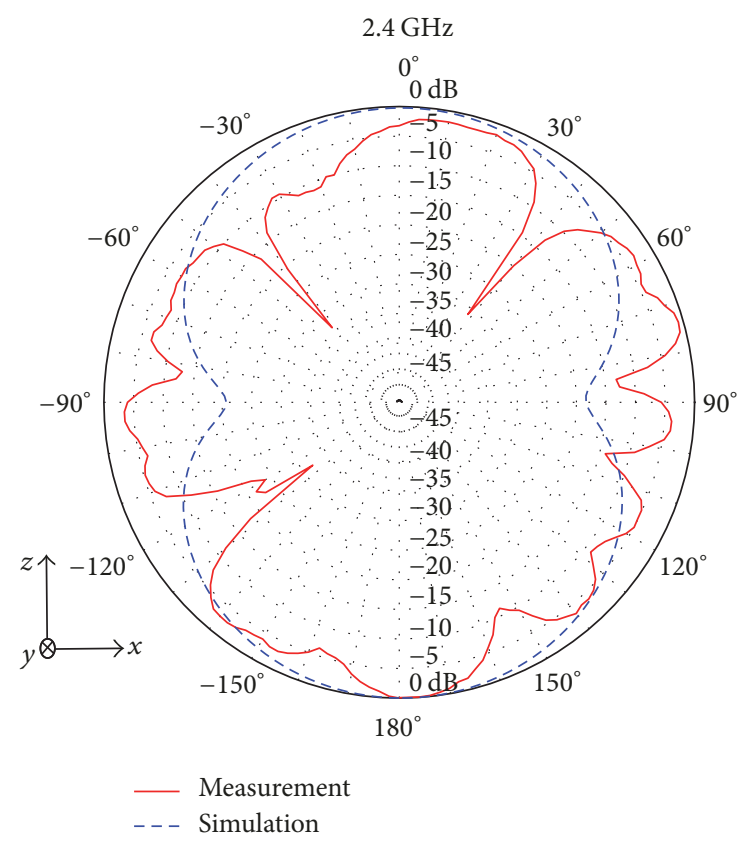

(a)

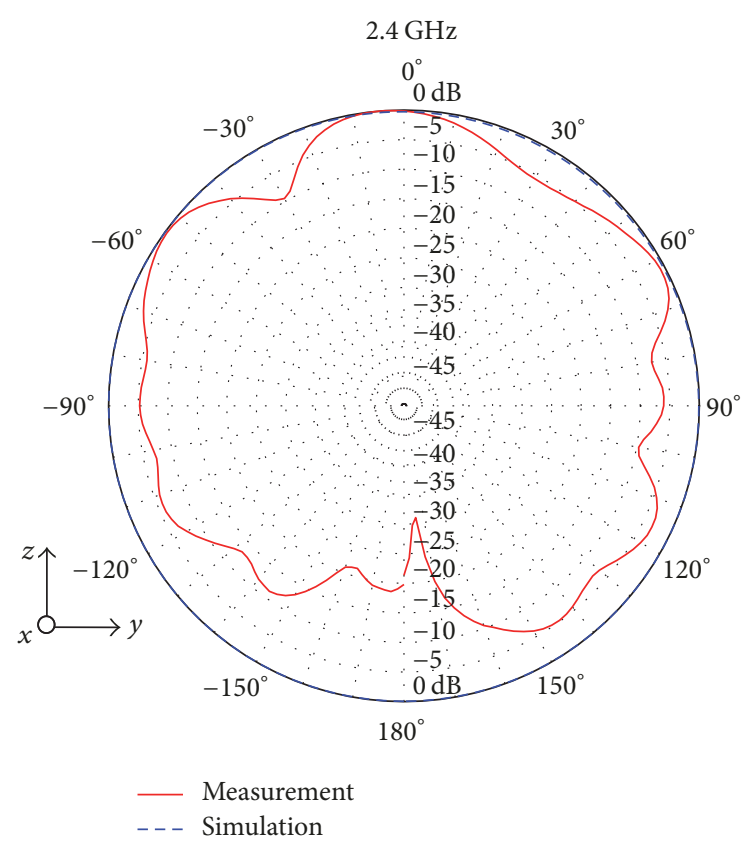

(c)

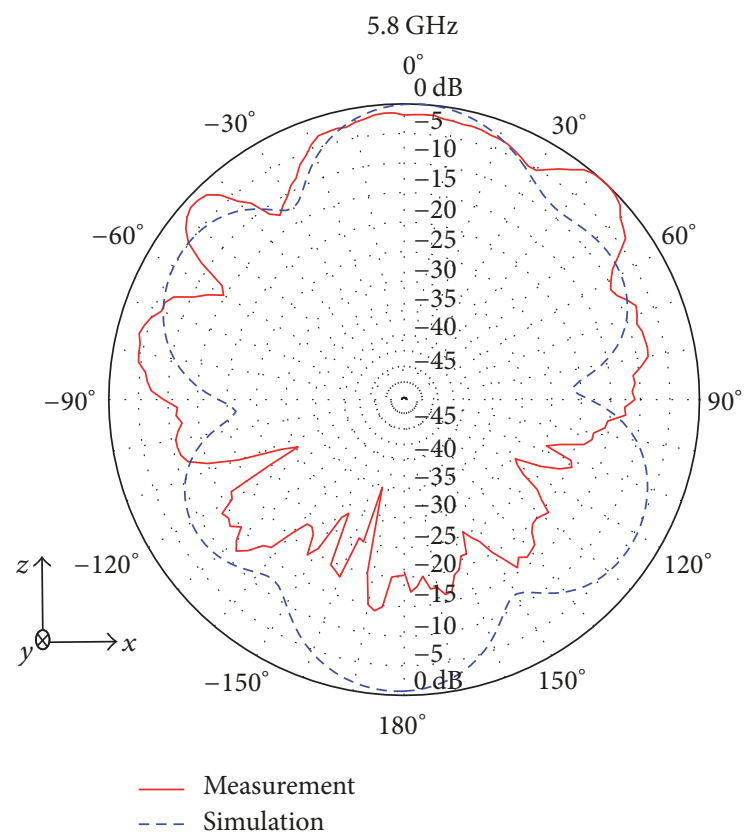

(b)

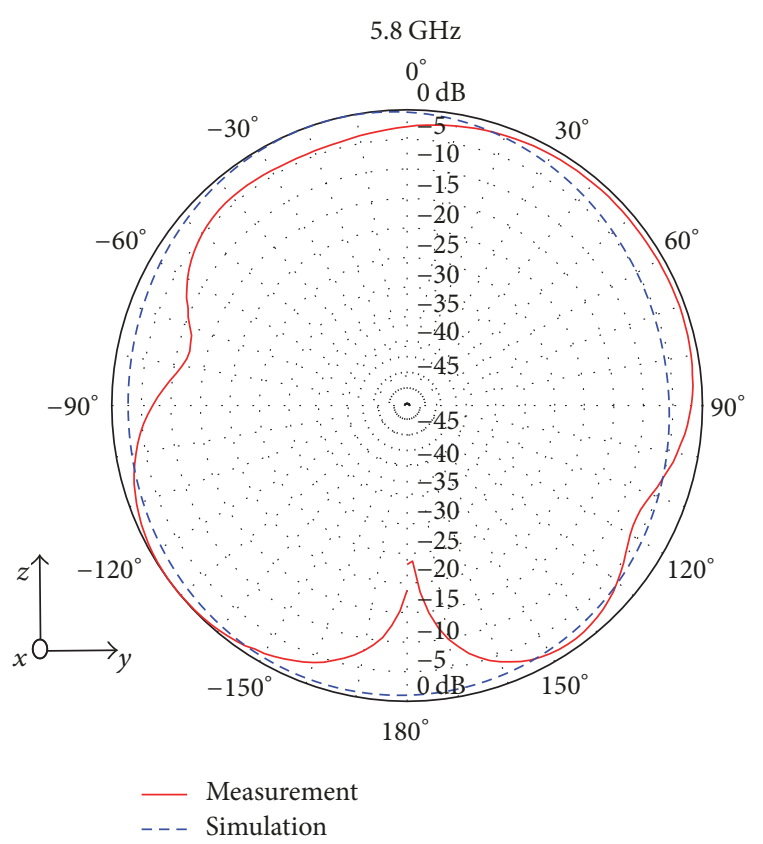

(d)

Figure 11: Measured radiation pattern of the realized antenna at $2.5 \mathrm{GHz}(X Z$ plane (a) and $Y Z$ plane (c)) and $5.8 \mathrm{GHz}(X Z$ plane (b) and $Y Z$ plane (d)).

\section{Conflicts of Interest}

The authors declare that they have no conflicts of interest.

\section{Acknowledgments}

The authors have to thank Mr. Mohamed Latrach, Professor in ESEO, Engineering Institute in Angers, France, for allowing them to use all the equipment and electromagnetic solvers available in his laboratory.

\section{References}

[1] M. Cheney, Tesla Man Out of Time, Prentice-Hall, Englewood Cliffs, NJ, USA, 1981.

[2] H. Yagi and S. Uda, "On the feasibility of power transmission by electric waves," in Proceedings of the third Pan-Pacific Science Congress, vol. 2, pp. 1305-1313, Tokyo, Japan, 1926.

[3] U.S department of commerce, "Electric light without current," The Literary Digest, vol. 112, no. 3, p. 30, 1932. 
[4] W. C. Brown, "The history of power transmission by radio waves," IEEE Transactions on Microwave Theory and Techniques, vol. 32, no. 9, pp. 1230-1242, 1984.

[5] W. C. Brown, "The amplitron: a super power microwave generator," Electron Progress, vol. 5, no. 1, pp. 1-5, 1960.

[6] W. C. Brown, "The history of the crossed-field amplifier," IEEE MTT-S Newsletters, no. 141, pp. 29-40, 1995.

[7] W. C. Brown, "Electronic and mechanical improvement of the receiving terminal of a free-space microwave power transmission system," NASA Report CR-135194 4964, Raytheon Company, Wayland, MA, USA, August 1977.

[8] W. Brown and J. Triner, "Experimental thin-film, etched-circuit rectenna," in Proceedings of the MTT-S International Microwave Symposium Digest, pp. 185-187, Dallas, TX, USA, June 1982.

[9] P. Koert, J. Cha, and M. Machina, “35 and $94 \mathrm{GHz}$ rectifying antenna systems," in Proceedings of the 2nd International Symposium on SPS 91-Power from Space, Gif-sur-Yvette, France, August 27-30, 1991.

[10] S. S. Bharj, R. Camisa, S. Grober, F. Wozniak, and E. Pendleton, "High efficiency C-band 1000 element rectenna array for microwave powered applications," in Proceedings of the 1992 IEEE MTT-S International Microwave Symposium Digest Part 2 (of 3), pp. 301-303, June 1992.

[11] J. Zbitou, M. Latrach, and S. Toutain, "Hybrid rectenna and monolithic integrated zero-bias microwave rectifier," IEEE Transactions on Microwave Theory and Techniques, vol. 54, no. 1, pp. 147-152, 2006.

[12] T.-W. Yoo and K. Chang, "Theoretical and experimental development of 10 and $35 \mathrm{GHz}$ rectennas," IEEE Transactions on Microwave Theory and Techniques, vol. 40, no. 6, pp. 1259-1266, 1992.

[13] P. Lu, X. S. Yang, and J. L. Li, "A compact frequency reconfigurable rectenna for 5.2- and 5.8-ghz wireless power transmission," IEEE Transactions on Power Electronics, vol. 30, no. 11, pp. 6006-6010, 2015.

[14] M. Zeng, A. S. Andrenko, X. Liu, Z. Li, and H.-Z. Tan, "A compact fractal loop rectenna for RF energy harvesting," IEEE Antennas and Wireless Propagation Letters, vol. 16, pp. 24242427, 2017.

[15] M.-J. Nie, X.-X. Yang, G.-N. Tan, and B. Han, "A compact 2.45GHz broadband rectenna using grounded coplanar waveguide," IEEE Antennas and Wireless Propagation Letters, vol. 14, pp. 986-989, 2015.

[16] S. V. Georgakopoulos and O. Jonah, "Optimized wireless power transfer to RFID sensors via magnetic resonance," in Proceedings of the 2011 IEEE International Symposium on Antennas and Propagation and USNC/URSI National Radio Science Meeting (APSURSI '11), pp. 1421-1424, Spokane, Wash, USA, July 2011.

[17] J. J. Schlesak, A. Alden, and T. Ohno, "Microwave powered high altitude platform," in Proceedings of the 1988 IEEE MTT-S International Microwave Symposium Digest: Microwaves-Past, Present and Future, pp. 283-286, 1988.

[18] S. Sasaki, K. Tanaka, and K. Maki, "Microwave power transmission technologies for solar power satellites," Proceedings of the IEEE, vol. 101, no. 6, pp. 1438-1447, 2013.

[19] V. Talla, B. Kellogg, B. Ransford, S. Naderiparizi, S. Gollakota, and J. R. Smith, "Powering the next billion devices with Wi-Fi," in Proceedings of the the 11th ACM Conference, pp. 1-13, Heidelberg, Germany, May 2015.

[20] B. B. Mandelbrot, Fractals: Form, Chance and Dimension, les Objets Fractals : Forme Hasard et Dimension, Nouvelle Bibliothèque Scientifiques, 1975.
[21] E. L. Barreto and L. M. Mendonça, "A new triple band microstrip fractal antenna for C-band and S-band applications," Journal of Microwaves, Optoelectronics and Electromagnetic Applications, vol. 15, no. 3, pp. 210-224, 2016.

[22] P. N. Rao and N. V. S. N. Sarma, "Koch fractal boundary single feed circularly polarized microstrip antenna," Journal of Microwaves, Optoelectronics and Electromagnetic Applications, vol. 6, no. 2, pp. 406-413, 2007.

[23] A. N. Jabbar, "Studying the effect of building block shape on sierpinski tetrahedron fractal antenna behavior using FDTDequivalent electric circuits," Journal of Microwaves, Optoelectronics and Electromagnetic Applications, vol. 11, no. 1, pp. 162173, 2012.

[24] N. Kushwaha and R. Kumar, "Study of different shape electromagnetic band gap (EBG) structures for single and dual band applications," Journal of Microwaves, Optoelectronics and Electromagnetic Applications, vol. 13, no. 1, pp. 16-30, 2014.

[25] T. Benyetho, J. Zbitou, L. El Abdellaoui, H. Bennis, A. Tribak, and M. Latrach, "A novel design of elliptic fractal multiband planar antenna for wireless applications," in Proceedings of the 1st URSI Atlantic Radio Science Conference (URSI AT-RASC '15), Gran Canaria, Spain, May 2015.

[26] W. Sierpiński, "On curves which contain the image of any given curve," Matematicheskii Sbornik, vol. 30, pp. 267-287, 1916.

[27] R. K. Mishra, R. Ghatak, and D. R. Poddar, "Design formula for sierpinski gasket pre-fractal planar-monopole antennas," Journals \& Magazines, IEEE Antennas and Propagation, vol. 50, no. 3, pp. 104-107, 2008.

[28] B. R. Franciscatto, T.-P. Vuong, and G. Fontgalland, "High gain Sierpinski Gasket fractal shape antenna designed for RFID," in Proceedings of the SBMO/IEEE MTT-S International Microwave \& Optoelectronics Conference (IMOC '11), pp. 239-243, IEEE, Natal, Brazil, October-November 2011. 


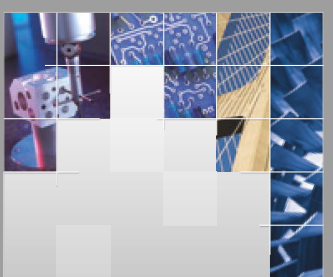

\section{Enfincering}
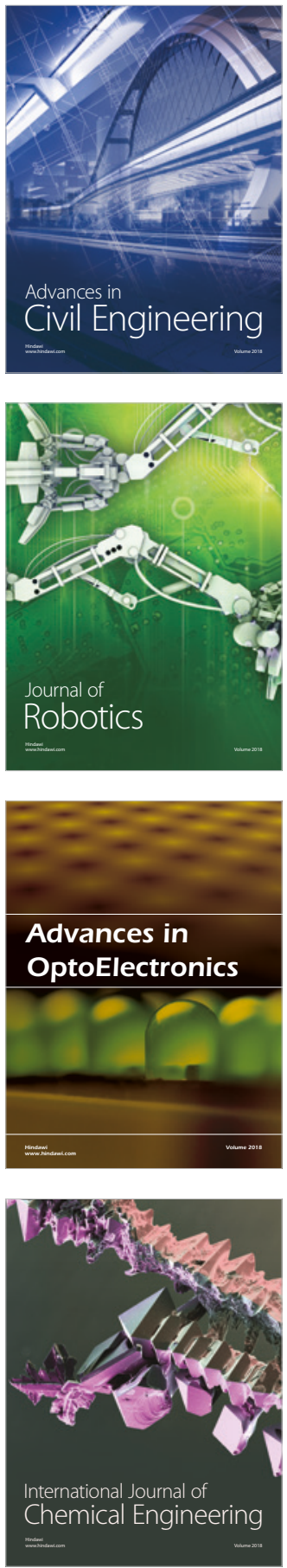

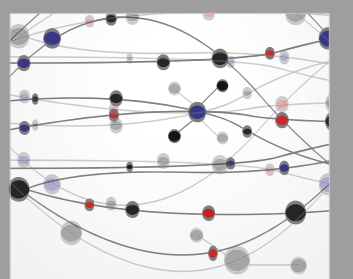

\section{Rotating \\ Machinery}

The Scientific World Journal

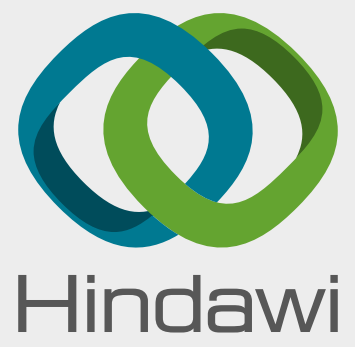

Submit your manuscripts at

www.hindawi.com
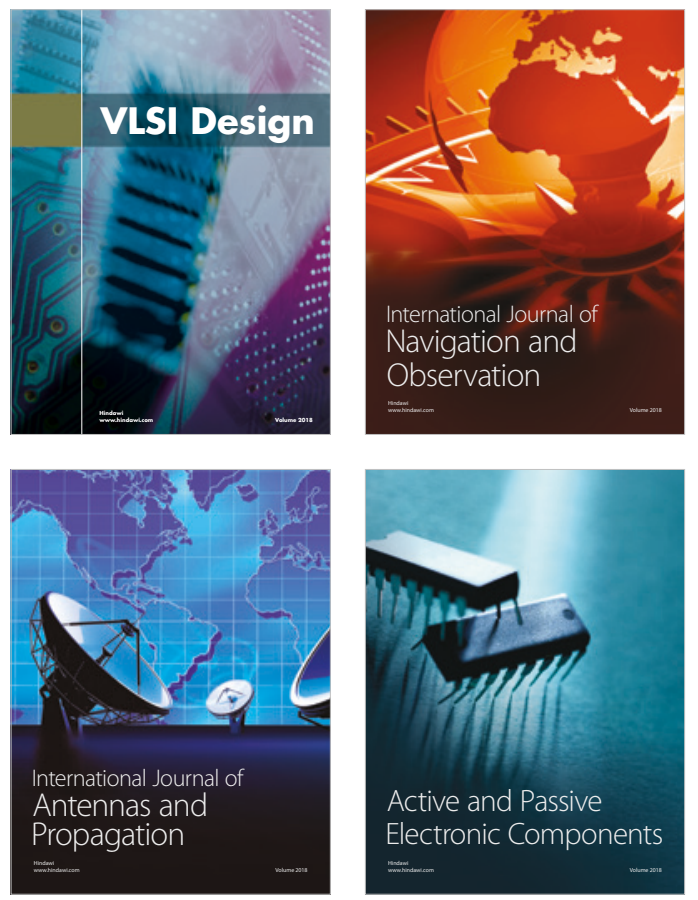
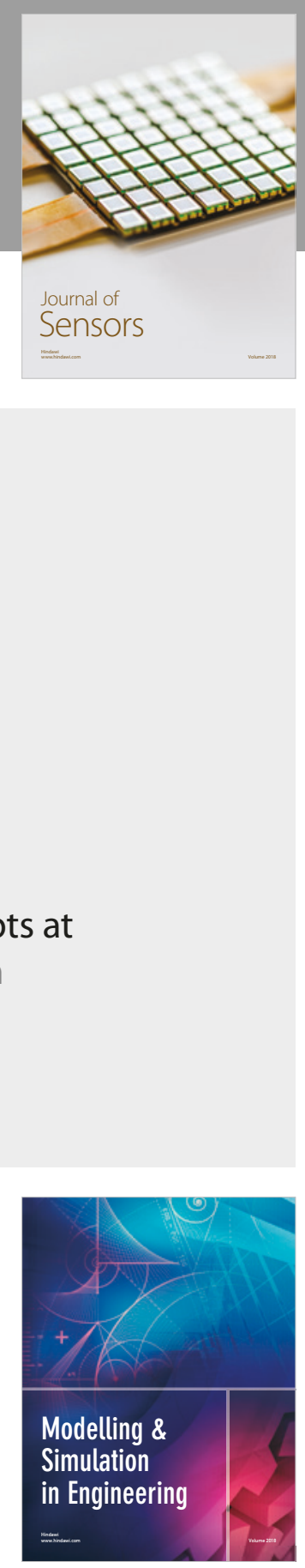

\section{Advances \\ Multimedia}
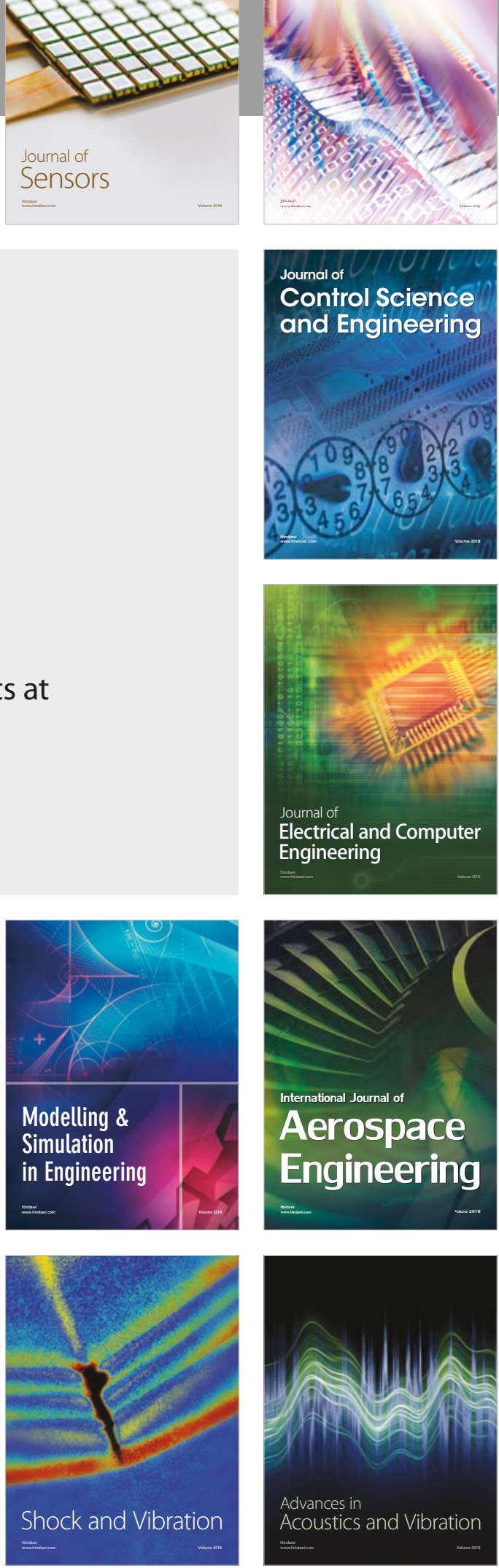